BLS 35, No 1 2009. DOI: http://dx.doi.org/10.3765/bls.v35i1.3630

(published by the Berkeley Linguistics Society and the Linguistic Society of America)

\title{
Focused N-Words and Double Negation Readings in Negative Concord Languages ${ }^{*}$
}

\author{
MICHELLE ST-AMOUR \\ University of Toronto
}

\section{Introduction}

The study of negation has long been a central issue in linguistic theory, as negation is employed in every language, yet there is no universal system for negation. In other words, there are many different patterns and intricate systems of negation found in different languages. This paper aims to investigate the interaction of negative operators and focus operators when negative words (n-words) are focused in Non-Strict Negative Concord languages.

Negative Concord (NC) languages use multiple instances of n-words in order to express negation:
Gianni *(non) ha telefonato a nessuno
G. not did call
to nobody
[Italian: Non-Strict NC]
'Gianni called nobody'
(2) Nessuno (*non) ha telefonato
nobody not did call
'Nobody called'
(3) Milan *(ne)vidi nikoho
M. neg.sees nobody
[Czech: Strict NC]
'Milan doesn't see anybody'

\footnotetext{
* Many thanks to Michela Ippolito and the University of Toronto Forum Class 2007-2008 for many thoughtful discussions and insightful comments. Thanks also to the audiences at the TOM Workshop in Semantics 1 (UofT, March 29-30, 2008) and the Canadian Linguistics Association Conference (UBC, May 31-June 2, 2008). This research is partially funded by a Social Science and Humanities Research Council (SSHRC) Grant to Andrea Gualmini.
} 
A Non-Strict Negative Concord language, such as Italian, employs a pre- and post-verbal asymmetry, in which n-words occurring post-verbally require overt sentential negation, as in (1), while pre-verbal n-words forbid overt sentential negation, as in (2). A Strict Negative Concord language, such as Czech, has no such asymmetry and sentential negation is required for all n-words, regardless of position, as in (3) and (4). This paper concentrates on Non-Strict Negative Concord languages only.

When an n-word in a Non-Strict NC language is focused, a Negative Concord reading does not arise; the only reading that is available is a Double Negation reading:

$$
[\text { Nessuno }]_{\mathrm{F}} \text { ama nessuno }
$$

This paper concentrates on the Double Negation reading that arises with the interaction between focus and negation. I argue here against a previous analysis for this data (Zeijlstra 2004) and present a new approach that will account for a larger variety of focused n-word data.

The paper is organized as follows: the next section introduces the reader to Zeijlstra's (2004) syntactic analysis of Negative Concord, beginning first with his proposal for basic Negative Concord readings and then moving on to focused $\mathrm{n}$ words that yield a Double Negation readings in NC languages. Section 2 presents a new piece of data that is left unaccounted for under Zeijlstra's proposal. A new proposal for focused n-words, one that employs the alternative semantics of Rooth (1992), is presented in Section 3. Section 4 concludes the paper.

\section{Zeijlstra (2004) and Negative Concord}

\subsection{Zeijlstra's Syntactic Analysis of NC}

Zeijlstra (2004) argues that $n$-words in Negative Concord languages are inherently non-negative. He proposes a syntactic agreement solution, in which n-words are nonnegative indefinites that are syntactically marked for negation; that is, they carry a [uNEG] feature. This [uNEG] feature must be properly licensed by a [iNEG] feature.

In Non-Strict Negative Concord languages, such as Italian, the [iNEG] feature can be sentential negation (6) or a null negative operator (7):

(6) Non ha telefonato a nessuno

neg has called to nobody

'He hasn't called anybody'

$\left[\mathrm{NegP}\left[\mathrm{non}_{[\mathrm{iNEG}]}\left[\mathrm{vp}\right.\right.\right.$ ha telefonato a nessuno $\left.\left.{ }_{[\mathrm{HNEG}]}\right]\right]$ 
(7) Nessuno ha telefonato

nobody has called

'Nobody called'

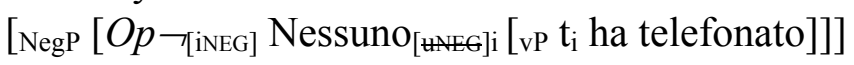

In (6), the [iNEG] feature of the sentential negation non checks the [uNEG] feature of the post-verbal n-word nessuno. In (7), on the other hand, the [iNEG] feature of the pre-verbal n-word nessuno is licensed by a null operator, since it is not properly c-commanded by an [iNEG] feature otherwise. In both (6) and (7), the [iNEG] undergoes syntactic agreement with the n-word carrying a [uNEG] feature.

\subsection{Zeijlstra's Treatment of Focused N-Words in NC}

As we saw above, Double Negation readings arise when n-words in Negative Concord languages are focused. According to Zeijlstra (2004), post-verbal nwords that are focused move covertly to FocusP, above the sentential negation, where the [UNEG] feature of the moved n-word is no longer licensed. As a repair strategy, a null negative operator, carrying an [iNEG], is inserted above the nword:

$$
\begin{aligned}
& \text { Non ho telefonato a [nessuno }]_{F} \\
& \text { Neg have called to nobody } \\
& \text { 'I didn't call nobody' = 'I called somebody' }
\end{aligned}
$$

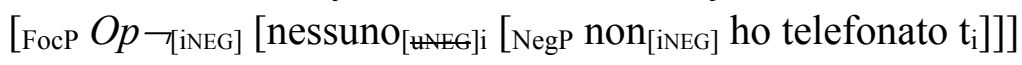

As a result, there are two [iNEG] features (one from the inserted null negative operator and one from the sentential negation) and a Double Negation reading results.

The same account can be used for focused pre-verbal n-words, such as (5) above, repeated here:

$$
\begin{aligned}
& {[\text { Nessuno }]_{\mathrm{F}} \text { ama nessuno }} \\
& \text { Nobody loves nobody } \\
& \text { 'Nobody loves nobody' }=\text { 'Everybody loves somebody' } \quad\left(\mathrm{DN},{ }^{*} \mathrm{NC}\right) \\
& {[\mathrm{FocP}[O p \rightarrow[\mathrm{iNEG}]} \\
& \text { Nessuno }
\end{aligned}
$$

The n-word nessuno begins in SpecVP, and moves to SpecTP, where there is a null negative operator that checks its [uNEG] features, identical to regular, unfocused n-words in subject position. In this derivation, however, the n-word is focused and thus moves even further to SpecFocP, according to Zeijlstra (2004).

The n-word is now left unlicensed once again. As a repair strategy, another null negative operator needs to be introduced into the structure. We are left with two $O p \neg$, both bearing [iNEG] features; the two negations cancel each other out as in classical logic and a Double Negation reading arises. 


\section{Focused N-Words and Double Negation Readings}

At this point, it seems as if Zeijlstra's (2004) proposal for focused n-words is equipped to handle the Double Negation reading in both the pre-verbal and the post-verbal environments. However, there is another possible structure in Italian that is left unaccounted for in Zeijlstra's (2004) treatment of focused n-words. I turn to this issue in the following subsection.

\section{Drawbacks to Zeijlstra's Proposal}

There are a few problems concerning Zeijlstra's (2004) proposal for Double Negation readings of focused n-words in Negative Concord languages, which I highlight in this subsection. In section 3, I propose a new approach to the focus data.

Although Zeijlstra's (2004) proposal outlined in the previous subsection can account for pre-verbal and post-verbal focused n-words, a problem arises when we consider data as in (10):

$[\text { Nessuno }]_{F}$ non ama nessuno

Nobody not loves nobody

'Nobody loves nobody' = 'Everybody loves somebody'

It appears as if the addition of the sentential negation non does not change the semantics of the construction, since (9) and (10) have the same Double Negation reading. Recall that Non-Strict Negative Concord languages, such as Italian, require sentential negation with post-verbal n-words yet prohibit sentential negation with pre-verbal n-words. What is interesting about the data found in (10) is that both a pre-verbal n-word and a post-verbal n-word are present. In this construction, sentential negation is optional. This optional sentential negation causes troubles for Zeijlstra's (2004) proposal, since his approach will not be able to account for the DN reading, as can be seen in (11):

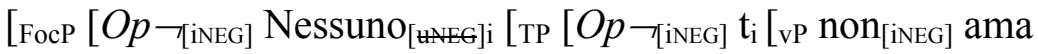

$$
\begin{aligned}
& \text { nessuno } \left.\left.\left[{ }_{[\mathrm{HEG}}\right]\right]\right]
\end{aligned}
$$

The derivation of (10) will be the same as for (9) above, only this time there is an additional [iNEG] from the sentential negation non. With the presence of three [iNEG] features, two of them will cancel each other out, leaving one [iNEG] for a negative reading. Therefore, according to the Zeijlstra-type approach, we should expect a Negative Concord reading for (10), which is unattested.

There are two possible ways that Zeijlstra could address this issue, in order to save his proposal in the face of this data. Since the problem lies in the fact that the structure in (11) has three [iNEG] features when it should only have two in order to get the proper Double Negation reading, it seems as if Zeijlstra must dispense of one of these negative operators. It may be possible to eliminate one of the [iNEG] features that license the pre-verbal n-word. Perhaps the [uNEG] feature of the pre- 
Michelle St-Amour

verbal n-word can be checked by the sentential negation's [iNEG] feature, as in (12), thus making the null operator in SpecTP unnecessary, as shown in (13):

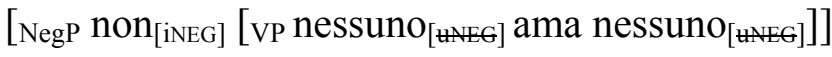

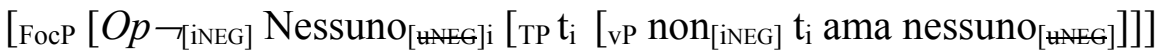

In (13), there are only two [iNEG] features, thus the proper Double Negation reading would arise. However, if this were the case, it is unclear how Zeijlstra (2004) would rule out this ungrammatical structure:

$$
\begin{aligned}
& \text { *Nessuno non ha visto Gianni } \\
& \text { nobody not has see G. } \\
& \text { 'Nobody saw Gianni' }
\end{aligned}
$$

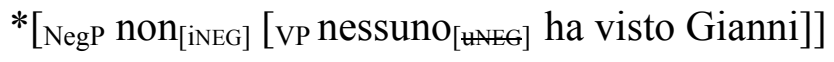

If (13) were a possible derivation, then (15) would be an equally possible derivation. However, (15) is not a possible derivation and (14) is an ungrammatical sentence in Italian. It is ungrammatical to have sentential negation with only a pre-verbal n-word in Non-Strict Negative Concord languages. Zeijlstra (2004) rules out sentences such as (14) by arguing that a pre-verbal n-word cannot be checked by sentential negation at some early point in the derivation; the preverbal n-word must be checked in its SpecTP position by a null operator. Since this null operator carries an [iNEG] feature, in order to check the [uNEG] feature of the n-word, it cannot co-occur with sentential negation, since this [iNEG] feature would cancel out the [iNEG] feature of the sentential negation and the proper Negative Concord reading would never arise. Since Zeijlstra (2004) must argue that (15) is not a proper derivation, he must also argue that (13) is not a proper derivation.

Another approach that Zeijlstra could take to this problem is to argue that the sentential negation in (10) is non-negative. If that were the case, Zeijlstra (2004) would be able to predict the proper Double Negation reading since there would be two [iNEG] features, instead of three, which caused the wrong Negative Concord reading in (16):

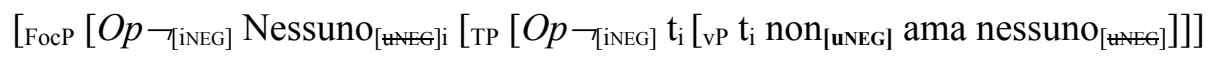

However, if we argue that the sentential negation in this case is non-negative, then we undermine the pillar of Zeijlstra's (2004) typological approach to Negative Concord languages. Zeijlstra argues that the difference between Strict Negative Concord languages and Non-Strict Negative Concord languages is that the sentential negation in the former is non-negative, while the sentential negation in the latter is negative. Therefore, if we argue that the sentential negation non in 


\section{Focused N-Words and Double Negation Readings}

(10) is non-negative, then we are arguing that a Non-Strict Negative Concord language like Italian also has non-negative sentential negation. By doing so, we not only lose the distinction between the two types of Negative Concord systems, but we also lose the concise explanation of the pre-verbal/post-verbal asymmetry in Non-Strict Negative Concord languages. In Zeijlstra's treatment of Non-Strict Negative Concord, a pre-verbal n-word cannot co-occur with sentential negation since both the pre-verbal n-word and sentential negation carry [iNEG] features, and thus the proper Negative Concord reading would not arise:

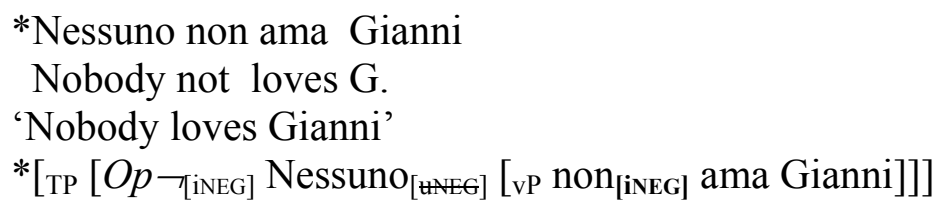

Zeijlstra (2004) is able to rule out the ungrammatical structure in (18) by arguing that the sentential negation in Italian, a Non-Strict Negative Concord language, is negative, and thus cannot co-occur with a pre-verbal n-word since there would be two [iNEG] features. Therefore, Zeijlstra argues that sentential negation in Italian is negative. As a result, the possible solution proposed above in (13), which requires a non-negative sentential negation, is not possible.

We have now seen that it is important for Zeijlstra's (2004) proposal to assume that the sentential negation in Italian is negative. But how then, are we going to get the proper interpretation of (10)?

The option of eliminating one of the [iNEG] features in (11) by allowing the pre-verbal n-word to be licensed by the sentential negation is not available, nor can we allow the sentential negation to be non-negative. We are once again in the situation where Zeijlstra's (2004) theory cannot account for the Double Negation reading of structures such as (10). As a result, we are forced to posit a new approach to these Double Negation readings in Negative Concord languages.

\section{A New Proposal of Focus and Negative Concord}

\subsection{Alternative Semantics and Focus}

In this paper, I assume that the focus operator introduces a set of alternatives containing both the proposition and at least one other proposition of the same form, à la Rooth (1992).

Rooth appeals to alternative semantics in order to account for focus data, which is similar to the question-answer paradigm. More specifically, the position of focus in an answer correlates with the question position in wh-questions and the position of disjoined alternatives in alternative questions:

Does Ede want tea or coffee? Who wants coffee?
Ede wants $[\text { coffee }]_{\mathrm{F}}$ $[\text { Ede }]_{\mathrm{F}}$ wants coffee 
The question Does Ede want tea or coffee determines the possible answers Ede wants tea and Ede wants coffee. Similarly, the focus phrase in the answer Ede wants [coffee] $]_{F}$ indicates that there are alternative answers of the form Ede wants $x$.

Semantically, focus introduces an additional focus semantic value: $[[\alpha]]^{f}$, where $\alpha$ is a syntactic phrase. This can be seen below in (19):

(19) $\left.\left[[\text { Ede wants [coffee }]_{\mathrm{F}}\right]\right]^{f}=$ the set of propositions of the form Ede wants $y$ $\left[\left[[\text { Ede }]_{\mathrm{F}} \text { wants coffee }\right]\right]^{f}=$ the set of propositions of the form $x$ wants coffee

Rooth argues that the alternative semantics approach makes a weak claim because it relies on construction-specific rules. What is missing from the alternative semantics theory, according to Rooth, is the key fact that the alternative set has a different semantic status from the ordinary semantic value. The question-answer congruence introduces the set of alternatives by virtue of the semantics and pragmatics of questions (questions determine the set of possible answers), whereas focus seems to introduce this set of alternatives through presupposition. As a result, Rooth proposes a single focus operator, $\sim$, which introduces a presupposed alternative set:

(20) Where $\Phi$ is a syntactic phrase and $C$ is a syntactically covert semantic variable, $\Phi \sim C$ introduces the presupposition that $C$ is a subset of $[[\Phi]]^{f}$ containing $[[\Phi]]^{O}$ and at least one other element.

In the case of (19), the constraint introduced by the focus operator $\sim$ is that $C$ be a set of propositions of the form Ede wants y containing Ede wants coffee and at least one other proposition:

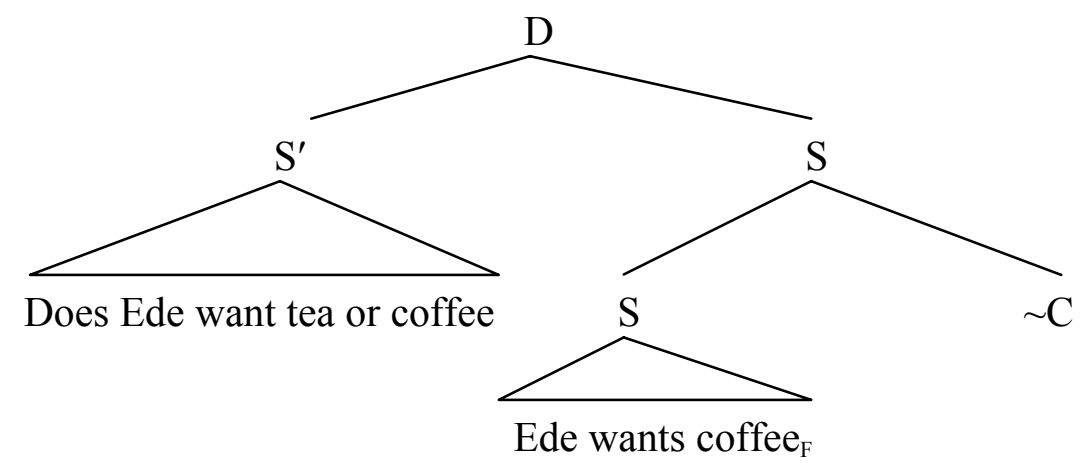

If the answer had focused on Ede instead, the focus operator would introduce the set of propositions of the form $x$ wants coffee, which would be inconsistent with the information contributed by the question.

The advantage of this focus operator is that it does not rely completely on question-answer configuration. Instead, the focus operator, $\sim$, introduces a variable which needs to pick out an antecedent, either from the linguistic context or from the discourse. 


\section{Focused N-Words and Double Negation Readings}

\subsection{Returning to Focused N-Words in NC}

In light of Rooth's (1992) theory of focus, we can now re-analyze the data presented above in (9). The focus operator introduces a set of alternatives containing nobody loves nobody and at least one other proposition of the same form, namely $x$ loves nobody:

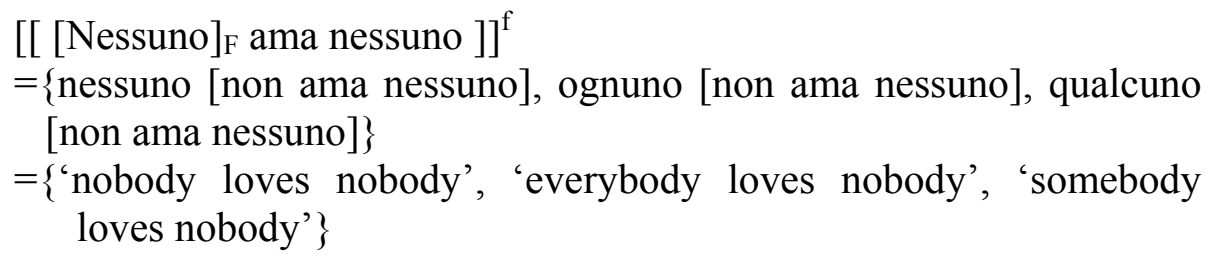

By focusing the pre-verbal n-word nessuno, in (22), we are introducing a set of alternatives. An important question arises at this point: what can qualify as an alternative? Since the list of alternatives is a set of utterances that could have been uttered, I assume here that an alternative must be grammatical. Since Italian is a Non-Strict Negative Concord language, sentential negation is required for postverbal $n$-words. Therefore, it is ungrammatical for an alternative to include a postverbal $\mathrm{n}$-word without sentential negation, as in (23):

$$
\begin{aligned}
& \text { *Qualcuno ama nessuno } \\
& \text { Somebody loves nobody } \\
& \text { 'Somebody loves nobody' }
\end{aligned}
$$

Therefore, we cannot simply take the focus value of (22) to be $x$ ama nessuno. Sentential negation must be inserted in order to make a grammatical alternative, a grammatical utterance that could have been said, as in (24):

Qualcuno non ama nessuno

Somebody not loves nobody

'Somebody doesn't love anybody'

Furthermore, the predicate in the set of alternatives must also express the same semantics as the predicate of the actual asserted proposition. The proposition in (22) expresses negation; therefore, the set of alternatives must also express negation. The only way for the alternative predicates to have the same negative semantics as the original proposition is to add sentential negation in order to yield $x$ non ama nessuno.

Therefore, in order for the alternatives to be grammatical, and in order to express the proper semantics, the set of alternatives must include sentential negation. Although the original focused version of (22) does not have overt sentential negation, I propose that non is inserted for the alternatives to properly license the $\mathrm{n}$-word in object position, to express the proper negative meaning of the sentence, and also to unsure that the alternatives are grammatical. The result is a coherent 
list of alternatives, with a negative predicate non ama nessuno. It is the addition of this extra negation in the predicate, whose presence was triggered by the focus operator, which gives rise to the Double Negation reading with focused n-words, as we will see below.

By focusing the subject n-word nessuno, the statement in (22) asserts that nobody has this property of loving nobody. The semantic value of this proposition is as follows:

$$
\begin{aligned}
& {\left[\left[[\text { Nessuno }]_{\mathrm{F}} \text { ama nessuno }\right]\right]^{\mathrm{O}}} \\
& =\neg \exists \mathrm{x} . \forall \mathrm{y}[\neg \operatorname{loves}(\mathrm{x}, \mathrm{y})] \\
& =\forall \mathrm{x} \cdot \exists \mathrm{y}[\operatorname{love}(\mathrm{x}, \mathrm{y})]
\end{aligned}
$$

Since there are two negative operators, one in the predicate and one in the subject $\mathrm{n}$-word, the two negatives cancel each other out and a DN reading arises. This approach yields the same reading as Zeijlstra (2004), and therefore, the reader may ask why one should abandon Zeijlstra's approach in favour of a Rooth-style system if both approaches yield the same results.

The advantage of adopting Rooth's theory of focus becomes apparent when we consider the data in (10) that Zeijlstra could not account for, repeated here:

$[\text { Nessuno }]_{\mathrm{F}}$ non ama nessuno

Nobody not loves nobody

'Nobody loves nobody' = 'Everybody loves somebody'

$(\mathrm{NC}, * \mathrm{DN})$

Recall that Zeijlstra (2004) could not account for the Double Negation reading of such a construction. I argue here that (26) can be accounted for with Rooth's theory of focus:

$$
\begin{aligned}
& {\left[\left[[\text { Nessuno }]_{\mathrm{F}} \text { non ama nessuno }\right]\right]^{\mathrm{O}}} \\
& =\neg \exists \mathrm{x} \cdot \forall \mathrm{y}[\neg \operatorname{loves}(\mathrm{x}, \mathrm{y})] \\
& =\forall \mathrm{x} \cdot \exists \mathrm{y}[\operatorname{love}(\mathrm{x}, \mathrm{y})]
\end{aligned}
$$

If we assume that the predicate non ama nessuno is a regular Negative Concord predicate with one negative operator (the sentential negation) and that the nword nessuno in object position is an inherently non-negative NPI-like constituent, then the structure in (27) has two negative operators (one in the predicate and one in the subject $\mathrm{n}$-word). In other words, the predicate non ama nessuno contains one negative operator and means $x$ loves nobody (the same as in the case of (25)). The proposition in (26) asserts that nobody has this property of loving nobody. The two negative operators will cancel each other out as in classical logic and thus we predict the proper Double Negation reading. 


\section{Focused N-Words and Double Negation Readings}

\section{Conclusion}

In this paper, I have investigated the interaction between n-words in Non-Strict Negative Concord languages and another scope-bearing element, namely focus operators.

When considering novel focus data, we uncovered drawbacks to Zeijlstra's (2004) proposal. His account is only able to predict a Double Negation reading when sentential negation is present with a post-verbal n-word and a focused preverbal $\mathrm{n}$-word, a reading that is unattested.

As a result, I provided an alternative proposal using Rooth's (1992) alternative semantics, in which the predicates in the set of alternatives require sentential negation. The focused $\mathrm{n}$-word then provides another negation, yielding two negative operators. The extra negation in the predicate, whose presence is triggered by the focus operator, together with the negative operator of the focused nword, gives rise to the Double Negation reading by canceling each other out.

What is left for future research is the interaction between negative operators and focus in Strict Negative Concord languages, such as Czech and Russian. In this slightly different system of multiple negation, a Double Negation reading does not arise when an n-word is focused:

Nikto ne lubit nikogo

nobody not loves nobody

[Russian]

'Nobody loves anybody'

(NC)

(29) $[\text { Nikto }]_{\mathrm{F}}$ ne lubit nikogo

nobody not loves nobody

'Nobody loves anybody'

(NC)

*'Everybody loves somebody’

$*(\mathrm{DN})$

Perhaps the lack of Double Negation reading in (29) can be attributed to the negative status of the n-words in Strict Negative Concord languages. In other words, n-words in Russian might all be inherently non-negative (à la Zeijlstra 2004) or NPIs (à la Ladusaw 1992), thus never yielding the two negative operators required for the Double Negation reading. I leave this for future research.

\section{References}

Ladusaw, William. 1992. Expressing negation. In C. Barker and D. Dowty, eds., SALT II: Proceedings of the Second Annual Conference on Semantics and Linguistic Theory, 237-259. (Ohio State University Working Papers in Linguistics 40.) Columbus, OH: Ohio State University Department of Linguistics.

Rooth, Mats. 1992. A theory of focus interpretation. Natural Language Semantics 1(1):75-116. 


\section{Michelle St-Amour}

Zeijlstra, Hedde. 2004. Sentential negation and negative concord. Ph.D. dissertation, University of Amsterdam.

Department of Linguistics

University of Toronto

130 St. George Street, room 6076

Toronto, Ontario

M5S 3H1

Canada

michelle.stamour@utoronto.ca 